\title{
Reactive Production Control - Information to Control a Production
}

\author{
Georg Kasakow ${ }^{1, a^{*}}$ and Jan C. Aurich ${ }^{1, a}$ \\ ${ }^{1}$ Institute for Manufacturing Technology and Production System (FBK), Gottlieb-Daimler-Str., \\ 67663 Kaiserslautern, Germany \\ apublications.fbk@mv.uni-kl.de \\ * Corresponding author. Tel.: +49-631-205-4210; Fax: +49-631-205-3304.
}

Keywords: Production Control; Flexibility; Changeability; Responsiveness.

\begin{abstract}
Sustainable protection and expansion of the competitiveness of the industrial location Germany is an important topic of current research. How can manufacturing companies in high wage countries counter the challenges of market turbulences? Crucial for the competitiveness of these companies is the compensation of wage and salary costs through highly efficient processes. A promising approach is to increase the responsiveness of a company. Responsiveness means, to react as quickly as possible to events or changes of the market, which are not yet evident and can not be foreseen at the time of production system planning. An increase of responsiveness enables companies to react quickly and flexible to market turbulences. The question arises, which market information are relevant, to which a company has to react as quickly as possible in order to handle market turbulence. This paper addresses this issue and identifies relevant information, that are already known during the phase of product development, and the unknown information of the market, to which an existing production system has to react in order to compensate market turbulences. The interplay of known and unknown information enables a responsive production control. The origin and usage of this information, which enables reactive production control, are a part of this article and are explained therein.
\end{abstract}

\section{Introduction}

An example for challenges events resulting from market turbulences was the opening of the commercial premises in e.g. Far East and Eastern Europe where the competition between the economies has increased [1]. Companies that are too slow in responding to this kind of events struggle for their existence [2]. To remain competitive, companies in high-wage countries have to rely on higher responsiveness and highly individualized products in order to be able to respond immediately on changing events and still be able to offer an additional benefit to a customer [1]. This will lead to individual customer orders and thus to make-to-order production processes [3]. A make-to-order production process entails high coordination efforts.

Customers, which order individual products, require products at a low price with high quality and short delivery times. This means that a company has to be flexible, meet a high adherence to delivery dates and continuously be cost-effective [4]. Additionally, the content of individual customer orders is unknown until a customer places his order. These are also challenges for a company, which can be handled through a higher responsiveness.

A high degree of flexibility enables the production of individual products. However, this entails a high effort in planning and control. It is possible to plan a production, but disturbing events lead to a new run through the planning process. An example for events that are responsible for such circumstances are late delivery of supplier parts, machine breakdown or production of scrap [5].

\section{Practical Need and Research Gap}

A fast reaction time is required to be able to respond quickly on changing events. A state of production differs from the planned state by means of incident. This creates a gap that has to be closed. For this purpose, it is required to create a new production plan. First, it is necessary to gather 
information about the current state of production. The slower the gathering, the greater is the difference between plan and reality [4]. In order to react quickly to changes, a representation of the current state is required. Information must be consistently available. This is the only way to change a production plan and adjust it [5]. This means that a production control has to be designed to minimize time and work effort to fulfill changes of the plan. For this reason, the process of adjusting the production plan has to be automated. Therefore, it is necessary to identify needed information to control a production automatically.

The basic objectives of a production are to achieve low production costs, high product quality and a short throughput time [6]. However, resulting from the globalization of the markets, flexibility and changeability are currently important requirements for a production. It is possible to transport products around the world and information are accessible from anywhere. As a result, companies in high-wage countries have to react quickly to the needs of the markets and to individual customer requirements in order to remain competitive [7]. This can be achieved through flexibility and changeability.

Flexibility means the ability to convert processes freely to changes in assembly and manufacture tasks. Changeability is the ability to adapt production systems quickly to changes in markets, products and technologies [8].

A company is considered as flexible and changeable if it is permanently adapted to changes. For this, the reaction time of the planning and control within the production has to be shortened, in order to be able to react as quickly as possible to changes. If, for example, a product changes, the process must adapt as quickly as possible [7]. This means that in case of customer-specific products, a production process is subject to permanent changes. The ideal production is able to produce single and customer individual products [6]. For this purpose, production plans must be reactively adapted. To achieve this, a production must be transparent. The current state of production must always be evident. A higher responsiveness to changes leads to a higher effectiveness. This means that transparency and responsiveness are the primary characteristics for a production. Transparency and responsiveness can be used to create control loops within a production process [4].

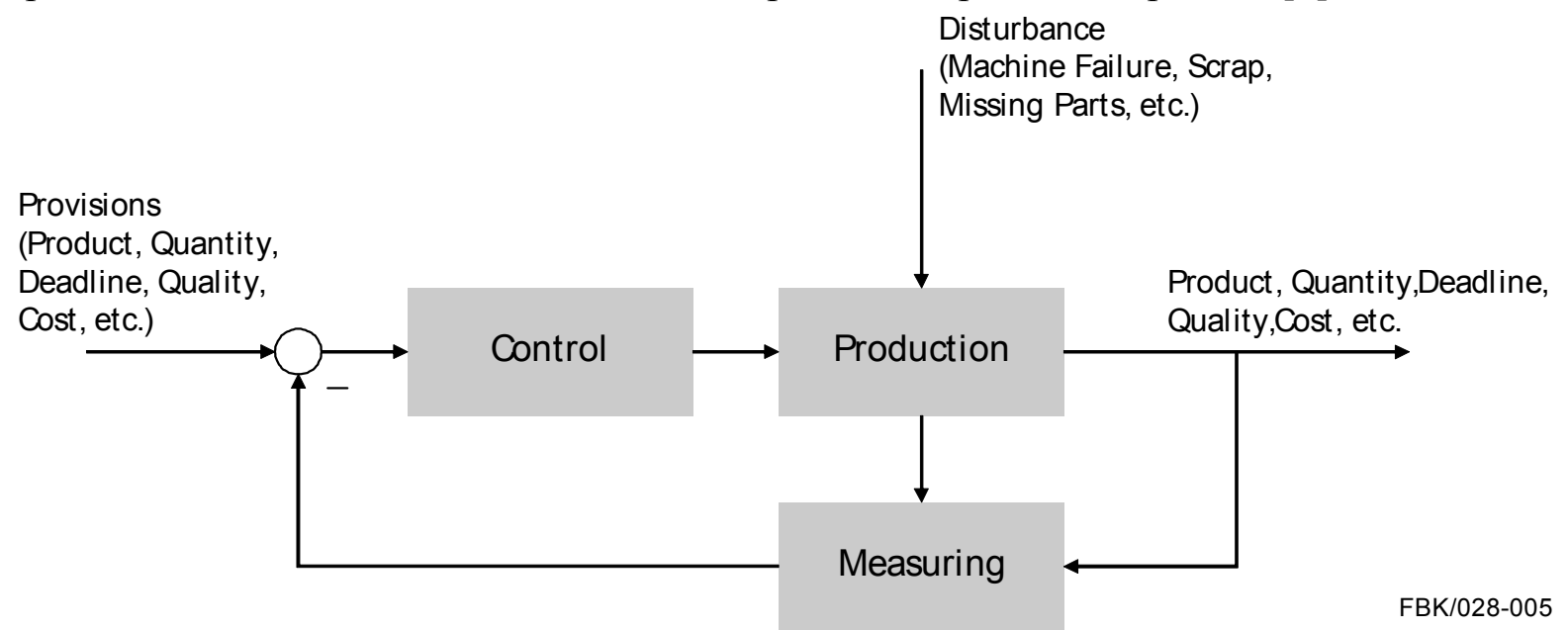

Fig. 1 Simplified schematic diagram of a production as a control loop [4].

The production control must respond to events. These are usually disturbances in production, such as machine failures, scrap, missing parts or absent employees [4]. By occurrence of such an event, the current state of production deviates from the planned state of production [9]. This creates a plan gap between target and actual.

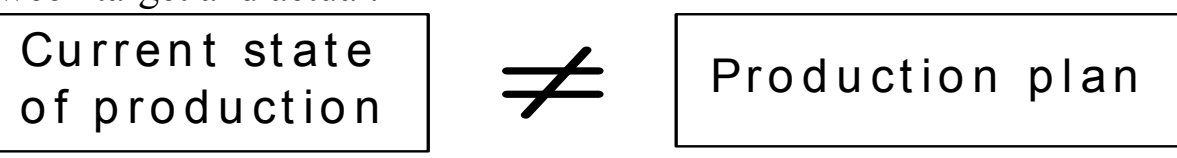

Fig. 2 Plan Gap. 
A production planner is responsible for the creation of a production plan [6]. In order to create a production plan, the company needs detailed information about the current state of production as well as planned activities. Both Kletti et al. [4] and Nyhuis et al. [10] describe that it is of advantage to train the planners better in these tasks, in order to achieve a higher changeability of a production system.

With regard to increasing flexibility, changeability and the associated requirements for transparency and responsiveness, it is necessary to automate the process of production control. Automation enables a more quickly execution of the planning processes [11]. A computer-aided automation of the planning process allows short planning times, which means a short reaction time as well as a high planning quality [12]. Thereby, processes become more agile and more efficient [13]. This enables a better adaptation of the entire process to individual requirements [14].

The production control hast to react to events as quickly as possible. If a planner does the workperformance of summarizing, evaluating and processing of information, this would lead to a higher period of time and thus not provide the fastest solution. For this reason, a method is required that reacts to events as quickly as possible by monitoring the current state of production and by adapting a production plan as a result to disturbances which would lead to the formation of a plan gap.

\section{Questions of Production Planning and Control}

The production plan must be adapted in order to close the plan gap. For this, it must be decided how to adjust the production plan. The literature reveals that process planning answers the questions - what, how and which - something has to be produced. The production control answers - how much, when, where and by whom - something has to be produced (Fig. 3) [15].

The answers to these questions provide the information that are necessary for the production planning and control and therefore are essential for an automated production control. As individual customer orders result in a make-to-order production, the answering to these questions is as followed:

\begin{tabular}{|c|c|c|}
\hline \multicolumn{3}{|c|}{ Question } \\
\hline What? & $\square$ & Product/Finished Part \\
\hline How? & $\sqsubset$ & Manufacturing Process \\
\hline Which? & $\sqsubset$ & Means of Production \\
\hline How much? & & Quantity \\
\hline When? & $\Gamma$ & Date/Sequence \\
\hline Where? & $\square$ & Workplace \\
\hline By whom? & 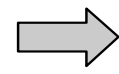 & Employee \\
\hline
\end{tabular}

FBK/028-007

Fig. 3 Questions of process planning and production control. 


\section{What?}

What has to be produced depends on the content of a customer order. It is possible that an external customer (end customer) or an internal customer (other department) places an order. The result of the order and thus the output of a production is a product. This product is a part with an assigned part number and description. This part (product) consists of subordinate parts, which again consist of further subordinate parts. This chaining of subordinated parts continues to the raw part and shows which parts are mounted in a product. Starting with the raw part, each subordinate part is processed within the production, in such way that a superordinate part and ultimately the final part (product) is created. A multi-level bill of material (BOM) describes how the entire chaining looks like and which parts are included in the final part (product) (Fig. 4).

The BOM derives from the content of an order. This leads to the fact that the content of an order and the derived BOM give information about what has to be produced.

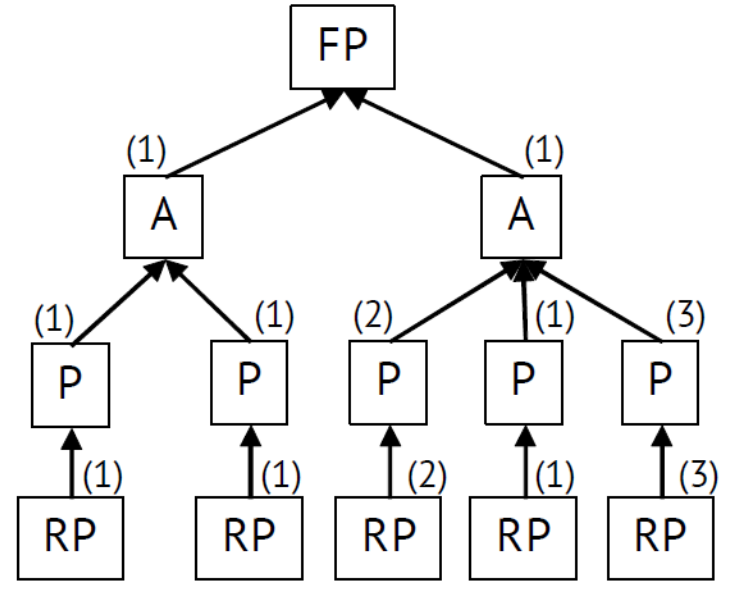

FP = Final Product

$A=$ Assembly

$\mathrm{P}=$ Part

RP $=$ Raw Part

() = Quantity

FBK/028-008

Fig. 4 Multi-level Bill of Material.

How?

How to produce something depends on what has to be produced. How to produce something is defined during the phase of product development. In this case, it is determined, that for example a bearing housing has to be turned and then milled. Thus, a manufacturing process is established, which can be used to produce a part. This defines a procedure for each part, how to produce it. The result is a defined routing plan. This means that for each part, a routing plan is established which determines during the phase of product development. Thus, there is a direct connection between routing plan and BOM. An example for a connection between routing plan and part shows Fig. 5 .

\begin{tabular}{|l|}
\hline Procedure Bearing Housing \\
Operation: Milling \\
Set-up Time: 20 \\
Production Time: 80 \\
Mass: 500 \\
Length: 90 \\
Width: 90 \\
Height: 6 \\
\hline
\end{tabular}

FBK/028-009

Fig. 5 Possible connection between routing plan and part [16]. 


\section{Which?}

Which means of production must be used, results from the routing plan that describes how to produce something. Thus, for the bearing housing mentioned in the previous section, initially a turning machine is necessary in order to perform the turning operations, and afterwards a milling machine for the milling operations. This shows that a turning and milling machine is required for the production of a bearing housing.

\section{How much?}

How much should be produced or the number of parts can be extracted from the BOM. The number of individual parts required for the production of a product is defined within the phase of product development and contains in a BOM. Thus, the number of parts that are required to produce a product can be anticipated in advance. Nevertheless, as described previously, the BOM derives from the customer's order. This means that the number of required parts is not determined until a customer places an order.

\section{Where?}

Where to produce something dependent on the location of the necessary production station. This means the workplace to process a part. This includes both, an assembly workplace and a stand of a production machine. If for example a milling machine is required, to process a bearing housing, it has a defined location within the production hall. Thus, each production station has its own location. To process a part by the necessary production station, it must be send to this location. Where to process a part depends on how it has to be processed.

By whom?

By whom a part has to be produced determines during the phase of product development. It is initially determined whether to produce a part by the company itself or order a finished part from a supplier. In case of in-house production, the part is to assign to the location of a production station and is to manufacture by the operator of this station.

\section{When?}

This question - when should be produced - can be expanded to the question - in which sequence something has to be produced. From the fact that it is decided when which part has to be produced, a sequence results of the parts that have to be produced. The occupancy of the production station and remaining production orders of other customers have an influence on this sequence. The sequence also depends on the strategy of order processing of a company. An example for this is the First-In First-Out Method.

\section{Preparation Within Product Development}

The consideration of these questions leads to the realization that it is possible to answer most of them during the phase of product development and use the resulting information for an automated production control. During the phase of product development, a product is developed and defined how it has to be produced. The answers to the remaining questions derives from the content of a customer order.

From the previous section, it is clear that the questions are interrelated (Fig. 6). How to produce depends on what to produce. The answer of the question - how to produce - leads to the answer to where and by whom. Thus answering these questions depends on what has to be produced. 


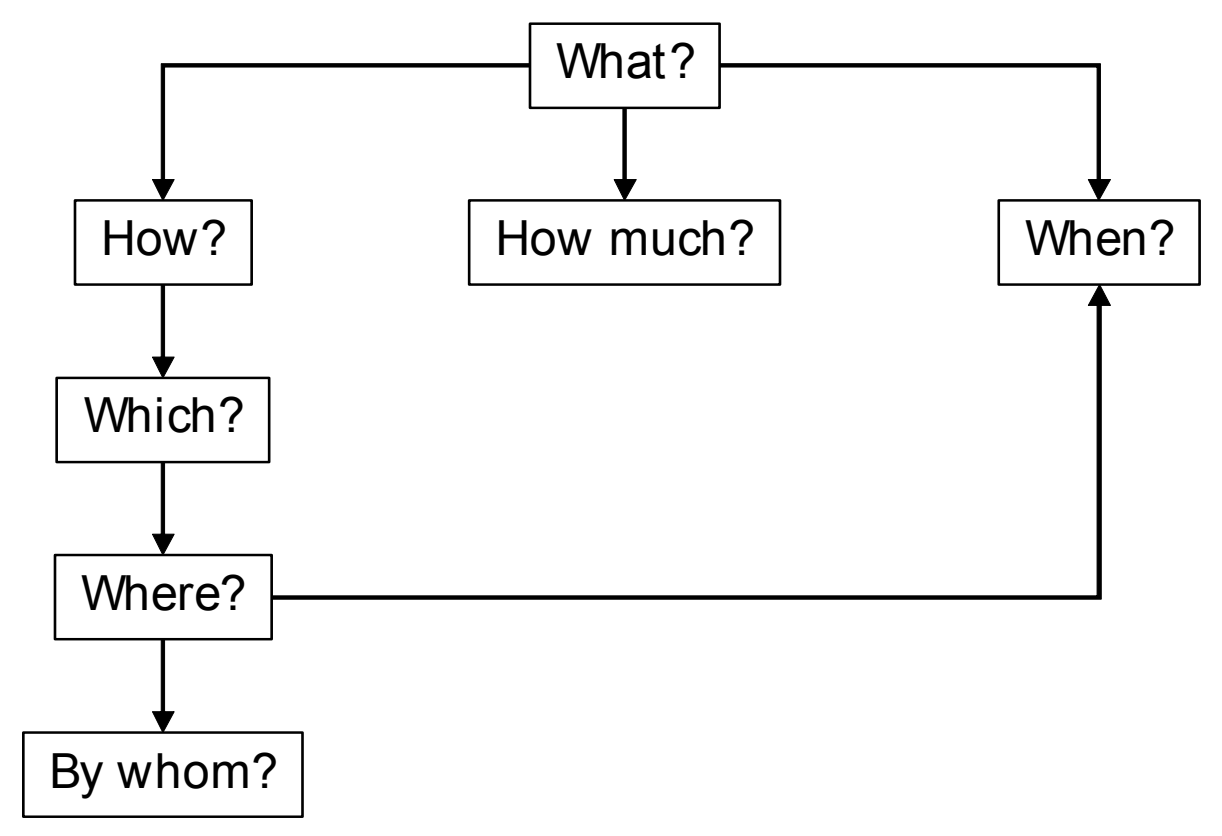

FBK/028-010

Fig. 6 Interrelation of questions.

Since a product is developed during product development and the company provides a possibility of individual configuration to the customer, the most important question remains: What kind of individual product will the customer order? In case of individual customer products the choice of combinational options are also defined during the phase of product development. The question what to produce - can not be answered prematurely, since this depends on the content of a customer order and is not clear until a customer places his order.

The questions of process planning can be given in advance during the phase of product development. The answer to the questions from the production control bases on the content of a customer order. This means that a customer order and its contents are decisive for the activities within a production process. Since the answer to the questions derives from what to produce and thus provides information on how to integrate an order into the production process. According to this, it is possible to control a production reactively to a customer order.

In order to use the information to control a production reactively on events, such as unpredictable individual customer orders, it is necessary to link the information to each single part in advance (Fig. 5). Due to the arrival of an individual customer order, the single parts can be combined to an individual BOM. This generates a linkage between the BOM and the routing plan. The BOM bases on the content of the individual customer order, whereby all necessary information from process planning and production control contains therein.

Such a BOM contains all required information to integrate an individual order into the production process and control all necessary tasks to manufacture the ordered product. This leads to the fact that based on the uncertainty of custom order placement the responsiveness of a company increases by using a linkage between BOM and routing plan.

\section{Exemplary Implementation}

To validate the approach of this paper an experimental setup was developed. It was realized through a Material Flow Simulation (MFS) that uses the linkage between the BOM and the routing plan. The setup bases on a Prototype Shop of a Turbo Charger Manufacturer, where development employees can place their individual orders for specific Turbo Charger to perform tests. 
The placement of an order starts the order processing. This generates a BOM that contains necessary information to control the production process as described previously. The MFS identifies the parts that are located at the end of the BOM chaining. These parts are raw parts that have to be purchased.

Within the MFS a random generator creates a delivery time for each of these raw parts. When the delivery time passes, the row parts are considered as delivered. At this moment it is possible to create a production order for the superordinate part and send the raw part to the necessary production station. The necessary information to the production station is part of the linked information. When the production order of a superordinate part is completed, the next production order can be created for the following part within the chaining of the BOM [16].

\section{Summary}

It is necessary to achieve a better responsiveness to market turbulences to protect and expand the competitiveness of a company in a high-wage county, especially in the context of individual customer orders. The best way to realize the most efficient responsiveness is to create an automated production control system. To do so it is necessary to know the information that are essential to control a production and link these information to each single part. Based on this linkage, it is possible to derive all necessary manufacturing tasks from the content of an individual customer order and control the production process automatically.

\section{Acknowledgement}

This research was funded by the German research foundation (DFG) within the IRTG 2057 "Physical Modeling for Virtual Manufacturing Systems and Processes".

\section{References}

[1] T. Bauernhansl, Die Vierte Industrielle Revolution - Der Weg in ein wertschaffendes Produktionsparadigma, in: T. Bauernhansl, M. Hompel, B. Vogel-Heuser (Eds.), Industrie 4.0 in Produktion, Automatisierung und Logistik, Springer-Verlag, Wiesbaden, 2014, pp. 5-34.

[2] H. Bullinger, Geleitwort, H. Bullinger, D. Spath, H. Warnecke, E. Westkämper (Eds.), in: Handbuch Unternehmensorganisation - Strategie, Planung, Umsetzung, Springer-Verlag, Berlin Heidelberg, 2009, pp. v-x.

[3] H. Jodlbauer, Produktionsoptimierung - Wertschaffende sowie kundenorientierte Planung und Steuerung, Springer-Verlag, Wien, 2007.

[4] J. Kletti, J. Schumacher, Die perfekte Produktion - Manufacturing Excellence durch Short Interval Technology (SIT), Springer-Verlag, Berlin Heidelberg, 2011.

[5] J. Kletti, Die Anforderungen an die moderne Produktion, in: J. Kletti (Eds.), MES Manufacturing Execution System - Moderne Informationstechnologie unterstützt die Wertschöpfung, second ed., Springer-Verlag, Berlin Heidelberg, 2015, pp. 1-18.

[6] K. Erlach, Wertstromdesign - Der Weg zur schlanken Fabrik, second ed., Springer-Verlag, Berlin Heidelberg, 2010.

[7] E. Westkämper, E. Zahn, Einführung, in: E. Westkämper, E. Zahn (Eds.), Wandlungsfähige Produktionsunternehmen - Das Stuttgarter Unternehmensmodell, Springer-Verlag, Berlin Heidelberg, 2009, pp. 1-5.

[8] E. Westkämper, C. Löffler, Strategien der Produktion - Technologien, Konzepte und Wege in die Praxis, Springer-Verlag, Berlin Heidelberg, 2016. 
[9] E. Abele, S. Bechtloff, J. Schumacher, Den Kundenwunsch erfüllen - Erhöhung der Termintreue durch individuell abgestimmten IT-Einsatz: submitted to Werkstatt + Betrieb (2009).

[10]D. Berkholz, Wandlungsfähige Produktionssysteme - der Zukunft einen Schritt voraus, in: P. Nyhuis, G. Reinhart, E. Abele (Eds.), Wandlungsfähige Produktionssysteme - Heute die Industrie von morgen gestalten, Verlag PZH, Hannover, 2008, pp. 13-18.

[11]R. D. Schraft, R. Kaun, Automatisierung der Produktion - Erfolgsfaktoren und Vorgehen in der Praxis, Springer-Verlag, Berlin Heidelberg, 1998.

[12]A. Kumpf, Anforderungsgerechte Modellierung von Materialflusssystemen zur planungsbegleitenden Simulation, Herbert Utz Verlag GmbH, München, 2001.

[13]F. Abolhassan, Einleitung, in: F. Abolhassan, J. Kellermann (Eds.), Effizienz durch Automatisierung - Das „Zero Touch“ -Prinzip im IT-Betrieb, Springer-Verlag, Wiesbaden, 2016, pp. 9-13.

[14]A. Botthof, Zukunft der Arbeit im Kontext von Autonomik und Industrie 4.0, in: A. Botthof, E. A. Hartmann (Eds.), Zukunft der Arbeit in Industrie 4.0, Springer-Verlag, Berlin Heidelberg, 2015, pp. 3-8.

[15]W. Eversheim, Organisation in der Produktionstechnik - Arbeitsvorbereitung, third ed., Springer-Verlag, Berlin Heidelberg, 2012.

[16]G. Kasakow, N. Menck, J.C. Aurich, Event-driven production planning and control based on individual customer orders, $49^{\text {th }}$ CIRP Conference on manufacturing Systems (2016) 434-438. 